\title{
Thinning Tall Spindle Apple Based on Estimations Made With a Hand-thinning Gauge
}

\author{
Thomas M. Kon ${ }^{1,2}$ and James R. Schupp ${ }^{1}$
}

\begin{abstract}
Additional index wORDs. crop load management, fruit set, fruit size, green fruit thinning, Malus $\times$ domestica, yield

Summary. Trials were conducted in 2009 and 2010 to evaluate the use of a hand-thinning gauge [Equilifruit; Institut National de la Recherche Agronomique (INRA), Montpelier, France] on three cultivars of apple (Malus

$\times$ domestica) trees trained to tall spindle. Hand-thinning treatments were applied after June drop to trees with supra-optimal crop loads. Three hand-thinning treatments were applied using the hand-thinning gauge: 1 ) thinning to $\approx 6$ fruit/ $\mathrm{cm}^{2}$ branch cross-sectional area (BCSA) (F value), 2) subtracting the delta value [ $\Delta$ (an adjustment factor to increase or decrease the number of fruit per BCSA] from the $F$ value $(F-\Delta)$, and 3$) F-2 \Delta$. These treatments were compared with a control and a traditional hand-thinning heuristic of spacing a solitary fruit every 7 to 8 inches of branch length. Use of the hand-thinning gauge generally improved fruit weight and maintained whole tree yields when compared with the control. Hand-thinning based upon traditional fruit-spacing heuristics reduced crop density and increased final fruit weight of apple, but significant reductions in yield were observed in two of four studies when compared with the control. We find the hand-thinning gauge a useful tool in adjusting final crop load of apple.
\end{abstract}

$\mathrm{H}$ and-thinning, the physical removal of blossoms or immature fruit, can increase apple fruit size and quality at harvest. Maximal benefit of fruit size increase due to green fruit thinning occurred at or before $40 \mathrm{~d}$ after full bloom (Batjer et al., 1957). This corresponds to the period of time when chemical thinners are effective. Chemical thinning outcomes are highly variable because of multiple environmental and physiological factors, and sometimes due to managerial error. Hand-thinning is a very labor-intensive process, and growers report that obtaining a labor force in agriculture is becoming increasingly difficult (Gasperini, 2012). Therefore, hand-thinning after June drop is typically reserved for highvalue fresh market cultivars with excessive crop loads.

This project was funded by the Penn State Horticulture Department, USDA SCRI: Innovative Technologies for Thinning of Fruit, and the State Horticultural Association of Pennsylvania.

We thank the following for their contributions to this project: Celine Kuntz, Rich Marini, Evan Moore, Jen Rouzer, Melanie Schupp, and Edwin Winzeler. A special thanks to Dan Boyer of Ridgetop Orchards for bringing this technology to our attention. Appreciation is extended to Tara Baugher and Rob Crassweller for critical review of the manuscript.

${ }^{1}$ Plant Science Department, Penn State Fruit Research and Extension Center, Biglerville, PA 17307

${ }^{2}$ Corresponding author. E-mail: tmk243@psu.edu.
Given the stringent fruit size and quality standards demanded by markets and the occasional failure of chemical thinners, hand-thinning is still an important method of crop load management. In general, thinning guidelines emphasize spacing apples 6 to 10 inches throughout the canopy, and focus on removal of injured fruit, small fruit, and breaking up clusters (Gourley and Howlett, 1941). Thinning to a single fruit per cluster increased fruit size when compared with leaving two fruit per cluster, and reducing the number of fruit per spur increased fruit size when compared with equivalent treatments of removing entire clusters of fruit or selectively defruiting whole limbs within the canopy (Knight, 1980). Methods that emphasize small fruit removal improved fruit size and increased the value of the crop (Davison et al., 1979).

Pomologists use crop density (the number of fruit per unit branch or tree dimension) to express the balance of reproductive and vegetative growth of apple, and as a method to standardize fruit number per tree based on tree size (Lombard et al., 1988). Trunk size has a positive linear relationship with the fresh weight of the aboveground portion of the tree, and can be used to estimate potential bearing surface per unit land area (Westwood and Roberts, 1970). Subsampling the crop density of branches (number of fruit per square centimeter BCSA) is an early season sampling technique of whole tree crop density [number of fruit per square centimeter trunk cross-sectional area (TCSA)] (Uriu and Lilleland, 1959), and is effective in estimating the effects of fruit-thinning treatments on fruit number, yield, and mean fruit weight (Forshey and Elfving, 1979).

The Maitrise de la Fructification Concepts et Techniques (MAFCOT) group of the INRA in Montpellier, France, developed the centrifugal training system that partially manages crop load by the physical removal of flowering spurs (Lauri et al., 2004; Lespinasse and Lauri, 1999). The MAFCOT group developed a handheld tool (Equilifruit; INRA, Montpelier, France) as a guide for thinning by spur extinction (removal) and by fruit removal. The hand-thinning gauge is a small plastic disc with 11 semicircular notches of varying diameters (Fig. 1). At each notch, there is a whole number that is preceded by the letter $\mathrm{F}$ ( $\mathrm{F}$ value). The $\mathrm{F}$ value indicates the number of spurs or fruit to leave, based upon a final crop density of 6 fruit $/ \mathrm{cm}^{2}$ BCSA. The disc also provides $\Delta$, which allows the user a means of adjusting the intensity of hand-thinning treatment. To decrease or increase the number of fruit removed during hand-thinning treatment, $\Delta$ can be added or subtracted to the $\mathrm{F}$ value.

The objectives of this experiment were to evaluate a hand-thinning gauge

\begin{tabular}{lllc}
\hline $\begin{array}{l}\text { Units } \\
\text { To convert U.S. to SI, } \\
\text { multiply by }\end{array}$ & U.S. unit & SI unit & $\begin{array}{l}\text { To convert SI to U.S., } \\
\text { multiply by }\end{array}$ \\
\hline 0.3048 & $\mathrm{ft}$ & $\mathrm{m}$ & 3.2808 \\
2.54 & inch(es) & $\mathrm{cm}$ & 0.3937 \\
25.4 & inch(es) & $\mathrm{mm}$ & 0.0394 \\
6.4516 & inch $^{2}$ & $\mathrm{~cm}^{2}$ & 0.1550 \\
0.4536 & lb & $\mathrm{kg}$ & 2.2046 \\
0.0703 & $\mathrm{lb} / \mathrm{inch}^{2}$ & $\mathrm{~kg} \cdot \mathrm{cm}^{-2}$ & 14.2233 \\
28.3495 & $\mathrm{oz}$ & $\mathrm{g}$ & 0.0353
\end{tabular}


on multiple apple cultivars trained to tall spindle (Robinson et al., 2006), and to test the versatility of the thinning gauge by use of $\Delta$.

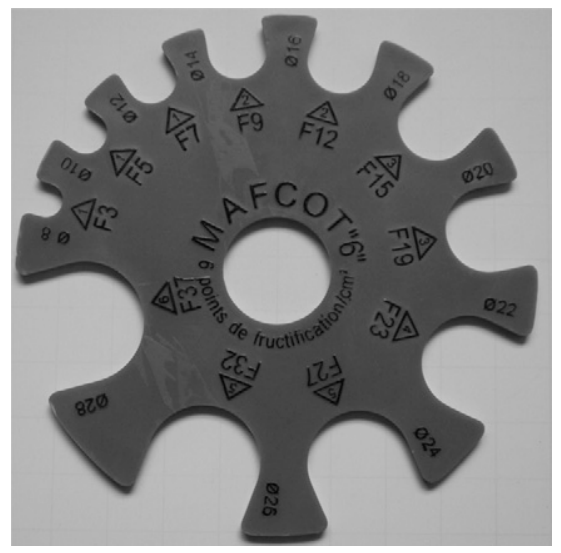

Fig. 1. The hand-thinning gauge [Equilifruit; Maîtrise de la Fructification - Concepts et Techniques (MAFCOT) group of the Institut National de la Recherche Agronomique (INRA), Montpellier, France]. At each notch, there are two corresponding values that are of interest to the user: the $F$ value [indicates the number of spurs or fruit to leave, based upon a final crop density of 6 fruit $/ \mathrm{cm}^{2}(38.7$ fruit/inch ${ }^{2}$ ) branch cross-sectional area (BCSA) $]$ and the delta value $[\Delta$ (an adjustment factor that can be added or subtracted to the $F$ value to decrease or increase the number of fruit removed during hand-thinning treatment)]. Branches are fitted with the handthinning gauge $3 \mathrm{~cm}$ (1.2 inches) from the trunk.

\section{Materials and methods}

'Golden DELICIOUs'. Handthinning experiments were conducted in 2009 and 2010 at the Pennsylvania State University's Fruit Research and Extension Center in Biglerville, PA. 'Golden Delicious' /'Budagovsky 9' (Bud 9) planted in 2004 at $5 \times 15-\mathrm{ft}$ spacing were used in this study. Despite two post-bloom applications of chemical thinners, trees had an excessive crop load. Fifteen uniform trees with a supraoptimal crop load were selected. Treatments were applied to whole trees as follows: 1) no additional thinning (control); 2) handthinned using the hand-thinning gauge F value; and 3 ) hand-thinned using a spacing heuristic of 7 to 8 inches between solitary fruit. All hand-thinning treatments were applied after June drop.

Limbs were fitted with the handthinning gauge $3 \mathrm{~cm}$ from the trunk. The notch that fit tightly around the circumference of the limb was selected. If the number of fruit on a given limb was higher than the corresponding $\mathrm{F}$ value, the number of fruit was reduced to the $\mathrm{F}$ value. Specifications of the hand-thinning gauge are presented in Table 1. The priority in which fruit were removed for handthinning gauge and heuristic treatments are as follows: 1) damaged fruit, 2) small fruit, and 3) to break up clusters of fruit. The experiment was replicated five times in a randomized complete block design.
'B U C KEYE G A L A' A N D 'HoneyCrisP'. To evaluate the handthinning gauge with small- and large-fruited cultivars, additional hand-thinning experiments were carried out on sixth leaf 'Buckeye Gala'/ 'M.9' (M.9) at $4 \times 15$-ft spacing and 'Honeycrisp'/'M.26' (M.26) at $5 \times$ 15-ft spacing in 2010. Despite two post-bloom applications of chemical thinners, trees had an excessive crop load. Fifteen uniform trees with a supraoptimal crop load were selected. Thirty uniform trees of each cultivar were selected and flagged. Handthinning treatments were applied to whole trees as follows: 1) control, 2) F value, 3) $\mathrm{F}-\Delta, 4) \mathrm{F}-2 \Delta$, and 5 ) hand-thinned using a spacing heuristic of 7 to 8 inches between solitary fruit. The experiments were replicated six times in a randomized complete block design.

Total fruit number per tree was counted after hand-thinning treatment and at harvest to determine crop density (number of fruit per square centimeter TCSA). Fruit from whole trees were harvested at commercial maturity for each cultivar, and all fruit were run through an electronic fruit sizer (Durand Wayland, LaGrange, GA). Fruit number per tree, crop density, yield, fruit weight, yield efficiency (yield per tree/TCSA), and fruit size distribution were determined. Because all hand-thinning treatments occurred after June drop, return bloom data were not collected. The personal computer

Table 1. Specifications of a hand-thinning gauge ${ }^{\mathrm{z}}$ that uses branch cross-sectional area (BCSA) as a predictor of target crop density of apple.

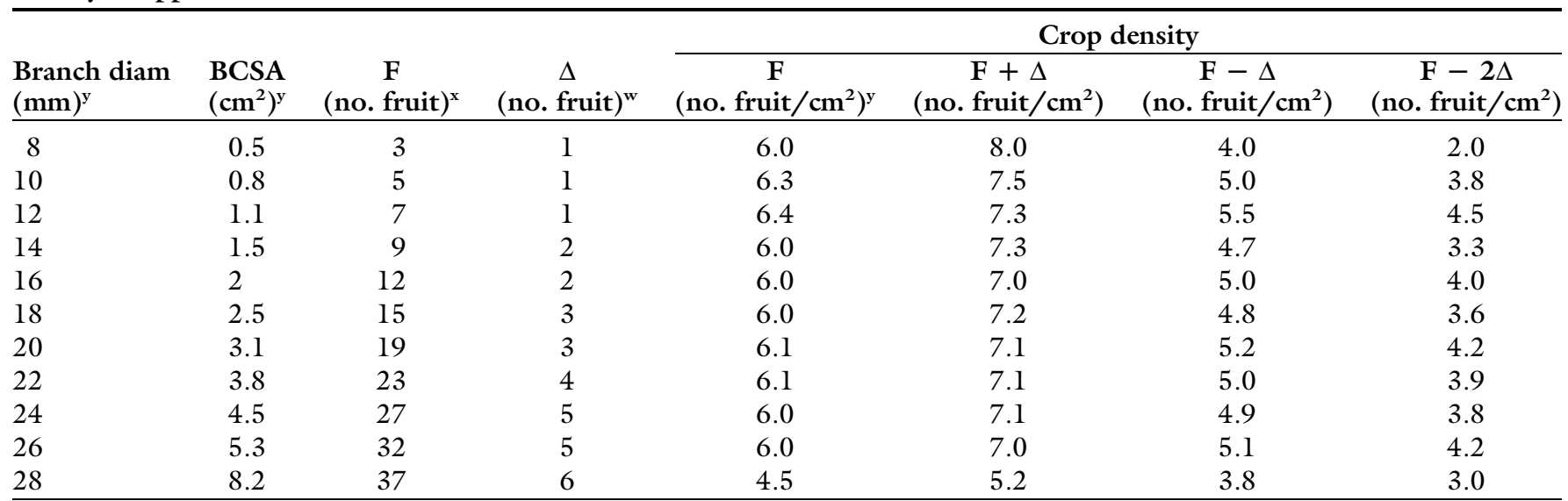

${ }^{2}$ Equilifruit was developed by the Maitrise de la Fructification - Concepts et Techniques (MAFCOT) group of the Institut National de la Recherche Agronomique (INRA), Montpellier, France. Branches were fitted with the hand-thinning gauge $3 \mathrm{~cm}(1.2$ inches $)$ from the trunk.

$\mathrm{y}=0.0394$ inch, $1 \mathrm{~cm}^{2}=0.1550 \mathrm{inch}^{2}, 1$ fruit $/ \mathrm{cm}^{2}=6.4516$ fruit $/$ inch $^{2}$.

${ }^{\mathrm{x}} \mathrm{F}$ is the target number of fruit remaining after hand-thinning treatment. Use of $\mathrm{F}$ will result in $\approx 6 \mathrm{fruit} / \mathrm{cm}^{2} \mathrm{BCSA}$.

"Delta $(\Delta)$ is an adjustment factor to increase or decrease the number of fruit per unit BCSA. To decrease or increase intensity of hand-thinning treatment, $\Delta$ is added or subtracted to $\mathrm{F}$. 
version of SAS (version 9.3; SAS Institute, Cary, NC) was used to carry out all statistical analysis. Tukey's honest significance test in PROC MIXED was used to test mean separation among treatments at $P=0.05$.

\section{Results and discussion}

'GolDEN DELICIOUS'. Fruit number and crop density of the control trees were moderately high in 2009 (181 fruit/tree and 10.5 fruit $/ \mathrm{cm}^{2}$ TCSA, respectively). In 2009 , trees thinned with the hand-thinning gauge did not differ from the control or the heuristic in any measurement (Table 2). When compared with the control, the heuristic reduced the number of fruit harvested per tree and crop density by $40 \%$, while increasing mean fruit weight by $59 \mathrm{~g}$. Yield and yield efficiency were unaffected by thinning treatment, likely because of a relatively narrow range of crop density among treatments.

Fruit number and crop density of 'Golden Delicious' control trees in 2010 were excessive (286 fruit/tree and 16.2 fruit $/ \mathrm{cm}^{2}$ TCSA, respectively). Mean fruit weight at harvest increased with hand-thinning gauge and heuristic treatments when compared with the control. Although both hand-thinning methods increased fruit size, use of the heuristic reduced yields by $30 \%$. This observed reduction in yield corresponds to final crop load. Thinning beyond a moderate level is counterproductive, because increased fruit size does not compensate for reduced yield (Forshey and Elfving, 1977). In 2010, crop density of 'Golden Delicious' trees thinned with the hand-thinning gauge were relatively high at 10.3 fruit $/ \mathrm{cm}^{2}$ TCSA. We speculate that this may be explained by variations in pruning from year to year. Final crop load of trees thinned with the hand-thinning gauge is a function of the total BCSA on a per tree basis. Therefore, annual, uniform pruning of the tall spindle system will theoretically result in uniform final crop loads from year to year. There was a positive upward shift in fruit size distribution in both years of the study for both hand-thinning treatments (Fig. 2). In general, the hand-thinning gauge was a more moderate treatment when compared with the heuristic.

'BuCKeye galA'. Control trees had an excessive crop load (214 fruit/ tree and 9.9 fruit $/ \mathrm{cm}^{2}$ TCSA), so

Table 2. Comparison of two hand-thinning treatments and an unthinned control on fruit number, crop density, yield, fruit weight, and yield efficiency of 'Golden Delicious' /'Budagovsky 9' apple in 2009 and 2010.

\begin{tabular}{|c|c|c|c|c|c|}
\hline $\begin{array}{l}\text { Thinning } \\
\text { treatment }\end{array}$ & $\begin{array}{c}\text { Fruit } \\
\text { (no./tree) }\end{array}$ & $\begin{array}{c}\text { Crop density } \\
\left.\text { (no. fruit } / \mathrm{cm}^{2} \text { TCSA) }\right)^{y}\end{array}$ & $\begin{array}{l}\text { Yield } \\
(\mathrm{kg})^{\mathrm{x}}\end{array}$ & $\begin{array}{c}\text { Fruit } \\
\text { wt }(g)^{x}\end{array}$ & $\begin{array}{c}\text { Yield efficiency } \\
\left(\mathrm{kg} \cdot \mathrm{cm}^{-2} \text { TCSA }\right)^{\mathrm{w}}\end{array}$ \\
\hline \multicolumn{6}{|c|}{2009} \\
\hline Control & $181 \mathrm{a}^{\mathrm{v}}$ & $10.5 \mathrm{a}$ & $31.5 \mathrm{a}$ & $178 \mathrm{~b}$ & $1.8 \mathrm{a}$ \\
\hline $\mathrm{F}^{\mathrm{u}}$ & $146 \mathrm{ab}$ & $8.4 \mathrm{ab}$ & $31.5 \mathrm{a}$ & $215 \mathrm{ab}$ & $1.8 \mathrm{a}$ \\
\hline Heuristic $^{t}$ & $110 \mathrm{~b}$ & $6.3 \mathrm{~b}$ & $26.1 \mathrm{a}$ & $237 \mathrm{a}$ & $1.5 \mathrm{a}$ \\
\hline \multicolumn{6}{|c|}{2010} \\
\hline Control & $286 \mathrm{a}$ & $16.2 \mathrm{a}$ & $36.4 \mathrm{a}$ & $129 a$ & $1.5 \mathrm{a}$ \\
\hline $\mathrm{F}$ & $175 \mathrm{~b}$ & $10.3 \mathrm{~b}$ & $32.6 \mathrm{ab}$ & $169 \mathrm{~b}$ & $1.4 \mathrm{a}$ \\
\hline Heuristic & $112 \mathrm{c}$ & $6.4 \mathrm{c}$ & $25.5 \mathrm{~b}$ & $195 \mathrm{c}$ & $1.0 \mathrm{~b}$ \\
\hline
\end{tabular}

${ }^{\mathrm{z}}$ Means of five observations.

${ }^{\mathrm{y}} \mathrm{TCSA}=$ trunk cross-sectional area; 1 fruit $/ \mathrm{cm}^{2}=6.4516$ fruit $/ \mathrm{inch}^{2}$

${ }^{\mathrm{x}} \mathrm{l} \mathrm{kg}=2.2046 \mathrm{lb}, \mathrm{l} \mathrm{g}=0.0353 \mathrm{oz}$.

"Yield efficiency = yield per square centimeter TCSA; $1 \mathrm{~kg} \cdot \mathrm{cm}^{-2}=14.2233 \mathrm{lb} /$ inch $^{2}$

"Mean separation within columns by Tukey's honest significance test at $P=0.05$.

${ }^{ } \mathrm{F}$ is the number of fruit remaining after hand-thinning treatment with the hand-thinning gauge [Equilifruit; Institut National de la Recherche Agronomique (INRA), Montpelier, France]. Use of F will result in $\approx 6$ fruit $/ \mathrm{cm}^{2}$ branch cross-sectional area (BCSA). Branches were fitted with the hand-thinning gauge $3 \mathrm{~cm}$ ( 1.2 inches) from the trunk.

'Trees were hand-thinned using a spacing heuristic of 7 to 8 inches (17.8 to $20.3 \mathrm{~cm}$ ) between solitary fruit.

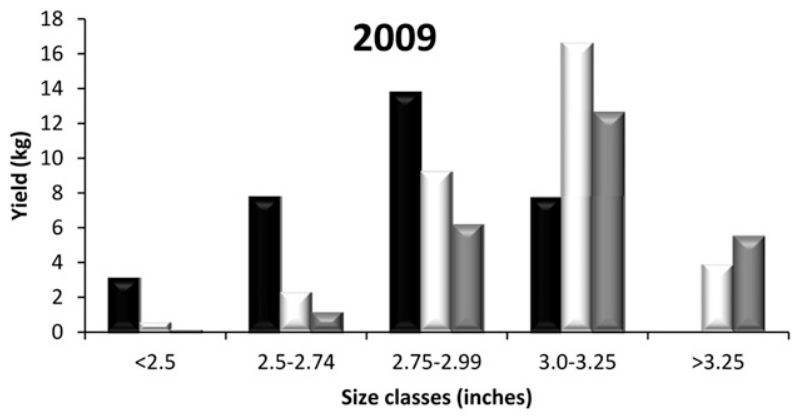

A)
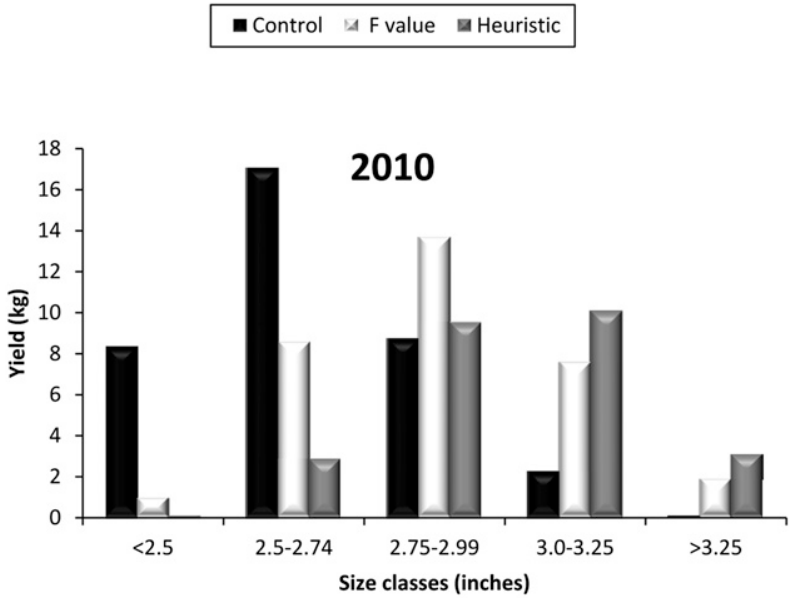

B)

Fig. 2. Fruit size distribution of three hand-thinning treatments imposed on 'Golden Delicious' apple in (A) 2009 and (B) 2010. The F value is the target number of fruit remaining after hand-thinning treatment with the hand-thinning gauge [Equilifruit; Institut National de la Recherche Agronomique (INRA), Montpelier, France]. Use of the F value will result in $\approx 6$ fruit $/ \mathrm{cm}^{2}$ (38.7 fruit/ inch $^{2}$ ) branch cross-sectional area (BCSA). Heuristic treatment entailed spacing a solitary fruit every 7-8 inches of branch length. Data are a summary of individual fruit weights of all fruit of whole trees, with five replicate trees per treatment; 1 inch $=2.54 \mathrm{~cm}, 1 \mathrm{~kg}=2.2046 \mathrm{lb}$.

hand-thinning treatments were justified (Table 3 ). Thinning with the $\mathrm{F}$ value and $\mathrm{F}-\Delta$ resulted in moderate crop loads. With the exception of $\mathrm{F}-2 \Delta$, hand-thinning treatments did not reduce yield. Yield efficiency of the 
F value was comparable to the control, while all other treatments were significantly reduced. All hand-thinning gauge treatments had a greater quantity of fruit $>3.0$ inches in diameter when compared with the control and heuristic (Fig. 3).

'HoneyCrisP'. Control trees had a moderate crop load $\left(7.3\right.$ fruit $/ \mathrm{cm}^{2}$ TCSA), which was variable from limb to limb. Use of the hand-thinning gauge $\mathrm{F}$ value and $\mathrm{F}-\Delta$ did not reduce crop load when compared with the control (Table 4). Robinson et al.
(2009) suggested that ideal fruit weights for 'Honeycrisp' range between 200 and $220 \mathrm{~g}$, and an ideal crop load to achieve this size is from 5 to 6 fruit $/ \mathrm{cm}^{2}$ TCSA. The control, $\mathrm{F}$ value, and $\mathrm{F}-\Delta$ had average fruit weights near the optimal fruit weight and/or posttreatment crop density. Both $\mathrm{F}-2 \Delta$ and heuristic treatments reduced crop density by $34 \%$ and $42 \%$, respectively, and increased average fruit weight above the target of 200 to $220 \mathrm{~g}$. In this study, the heuristic was the most severe thinning treatment,

Table 3. Comparison of four hand-thinning treatments and an unthinned control on fruit number, crop density, yield, fruit weight, and yield efficiency of 'Gala' /'M.9' apple in 2010. ${ }^{\mathrm{z}}$

\begin{tabular}{|c|c|c|c|c|c|}
\hline $\begin{array}{l}\text { Thinning } \\
\text { treatment }\end{array}$ & $\begin{array}{c}\text { Fruit } \\
\text { (no./tree) }\end{array}$ & $\begin{array}{c}\text { Crop density } \\
\text { (no. fruit } / \mathrm{cm}^{2} \text { TCSA) }\end{array}$ & $\begin{array}{l}\text { Yield } \\
(\mathbf{k g})^{x}\end{array}$ & $\begin{array}{c}\text { Fruit } \\
\text { wt }(g)^{x}\end{array}$ & $\begin{array}{c}\text { Yield efficiency } \\
\left(\mathrm{kg} \cdot \mathrm{cm}^{-2} \text { TCSA }\right)^{\mathrm{w}}\end{array}$ \\
\hline \multicolumn{6}{|c|}{2010} \\
\hline Control & $214 \mathrm{a}^{\mathrm{v}}$ & $9.9 \mathrm{a}$ & $28.9 \mathrm{a}$ & $137 \mathrm{~b}$ & $1.6 \mathrm{a}$ \\
\hline $\mathrm{F}^{\mathrm{u}}$ & $162 \mathrm{ab}$ & $6.3 \mathrm{~b}$ & $25.5 \mathrm{a}$ & $156 \mathrm{ab}$ & $1.2 \mathrm{ab}$ \\
\hline $\mathrm{F}-\Delta^{\mathrm{t}}$ & $122 \mathrm{~b}$ & $5.7 \mathrm{~b}$ & $20.9 \mathrm{ab}$ & $172 \mathrm{a}$ & $1.0 \mathrm{~b}$ \\
\hline$F-2 \Delta$ & $102 \mathrm{~b}$ & $3.6 \mathrm{c}$ & $16.2 \mathrm{~b}$ & $162 \mathrm{ab}$ & $0.9 \mathrm{~b}$ \\
\hline Heuristic ${ }^{s}$ & $144 \mathrm{~b}$ & $4.5 \mathrm{bc}$ & $22.3 \mathrm{ab}$ & $155 \mathrm{ab}$ & $1.1 \mathrm{~b}$ \\
\hline
\end{tabular}

${ }^{\mathrm{z}}$ Means of five observations.

yTCSA $=$ trunk cross-sectional area; 1 fruit $/ \mathrm{cm}^{2}=6.4516$ fruit $/$ inch $^{2}$

${ }^{x} 1 \mathrm{~kg}=2.2046 \mathrm{lb}, 1 \mathrm{~g}=0.0353 \mathrm{oz}$.

"Yield efficiency = yield per square centimeter TCSA; $1 \mathrm{~kg} \cdot \mathrm{cm}^{-2}=14.2233 \mathrm{lb} / \mathrm{inch}^{2}$

"Mean separation within columns by the Tukey's honest significance test at $P=0.05$.

${ }^{ } \mathrm{F}$ is the number of fruit remaining after hand-thinning treatment with the hand-thinning gauge [Equilifruit Institut National de la Recherche Agronomique (INRA), Montpelier, France]. Use of F will result in $\approx 6$ fruit $/ \mathrm{cm}^{2}$ branch cross-sectional area (BCSA). Branches were fitted with the hand-thinning gauge $3 \mathrm{~cm}(1.2$ inches) from the trunk.

${ }^{t}$ Delta $(\Delta)$ is an adjustment factor of the hand-thinning gauge, and is used to increase or decrease the number of fruit per unit BCSA. To decrease or increase intensity of hand-thinning treatment, $\Delta$ is added or subtracted to F.

sTrees were hand-thinned using a spacing heuristic of 7 to 8 inches $(17.8$ to $20.3 \mathrm{~cm})$ between solitary fruit.

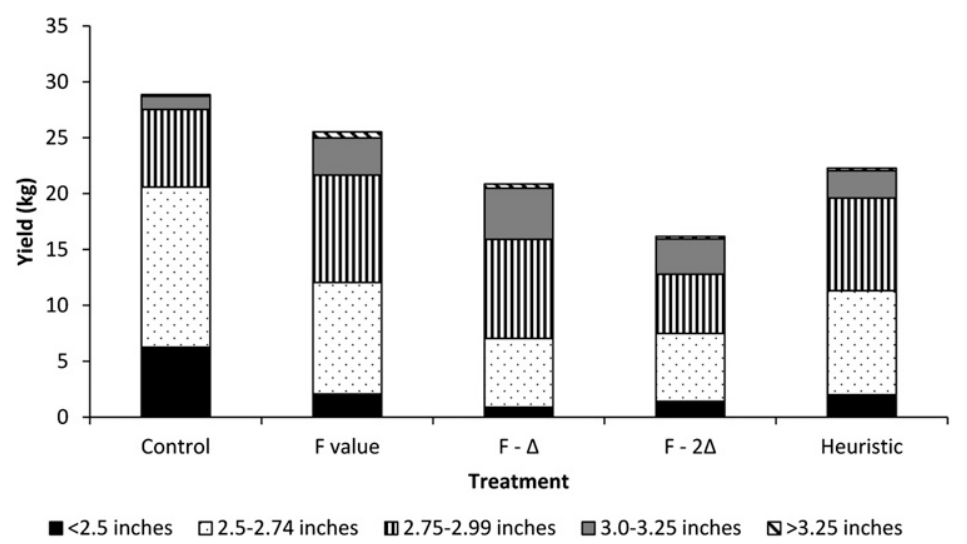

Fig. 3. Fruit size distribution of five hand-thinning treatments imposed on 'Buckeye Gala' apple in 2010. The $\mathrm{F}$ value is the target number of fruit remaining after handthinning treatment with the hand-thinning gauge [Equilifruit; Institut National de la Recherche Agronomique (INRA), Montpelier, France]. Use of the F value will result in $\approx 6$ fruit $/ \mathrm{cm}^{2}\left(38.7\right.$ fruit $/$ inch $\left.^{2}\right)$ branch cross-sectional area (BCSA). Delta $(\Delta)$ is an adjustment factor of the hand-thinning gauge, and is used to increase or decrease the number of fruit per unit BCSA. To increase intensity of hand-thinning treatment, $\Delta$ or $2 \Delta$ were subtracted from the $F$ value. Heuristic treatment entailed spacing a solitary fruit every 7 to 8 inches of branch length. Data are a summary of individual fruit weights of all fruit of whole trees, with six replicate trees per treatment; 1 inch $=2.54 \mathrm{~cm}, 1 \mathrm{~kg}=2.2046 \mathrm{lb}$.

as $88 \%$ of fruit were greater than 3.25 inches in diameter and $44 \%$ were greater than 3.5 inches in diameter (Fig. 4). 'Honeycrisp' is susceptible to bitter pit and several other postharvest disorders, and production of excessively large fruit is undesirable. We did not evaluate postharvest disorders in this study.

Because Honeycrisp is a largefruited cultivar that has a propensity to have "push-offs" due to short stem lengths and is prone to preharvest drop, fruit number per tree and crop density were presented at two specific intervals: immediately after treatment (posttreatment), and at harvest (harvested). Differences among treatments were observed with posttreatment fruit number and posttreatment crop load; however, there were no observed differences in harvested fruit number or harvested crop load. Since harvested crop density was similar among all hand-thinning treatments, there were no differences in yield.

The Equilifruit disc was originally developed to standardize spur extinction as a crop load management technique for the centrifugal tree training system (Lauri et al., 1995; Lespinasse and Lauri, 1999). Selective removal of spurs/fruiting sites has been shown to increase fruit size, fruit set of remaining spurs, and reduce the incidence of biennial bearing (Lauri et al., 2004; Tustin et al., 2012). When using the hand-thinning gauge for pruning, bearing surface is modified by reducing the number of fruiting structures per unit BCSA. In the centrifugal training system, primary modifications to bearing surface in the early years are made through spur removal rather than removal of epicormic shoots and thinning cuts. Conversely, bearing surface is primarily managed by thinning cuts in the tall spindle system. Since the management of bearing surface is different in these systems, one may anticipate that the use of the hand-thinning gauge may not be as applicable in a tall spindle system. Our results suggest the contrary. While we did not formally evaluate pruning as a factor in this experiment, the ratio of BCSA per unit TCSA should have a direct influence on whole tree crop load and yield. Further work will be conducted to determine the appropriate BCSA to TCSA ratio in tall spindle apple.

Growers often employ handthinning heuristics that rely on spacing 
Table 4. Comparison of four hand-thinning treatments and an unthinned control on posttreatment fruit number, harvested fruit number, posttreatment crop density, harvested crop density, yield, fruit weight, and yield efficiency of 'Honeycrisp' / 'M.26' apple in 2010. ${ }^{\mathrm{z}}$

\begin{tabular}{|c|c|c|c|c|c|c|c|}
\hline $\begin{array}{l}\text { Thinning } \\
\text { treatment }\end{array}$ & $\begin{array}{c}\text { Posttreatment } \\
\text { fruit (no./tree) }\end{array}$ & $\begin{array}{l}\text { Harvested fruit } \\
(\text { no./tree })^{\mathrm{x}}\end{array}$ & $\begin{array}{c}\text { Posttreatment crop } \\
\text { density (no. fruit/ } \\
\mathrm{cm}^{2} \text { TCSA) }\end{array}$ & $\begin{array}{c}\text { Harvested crop } \\
\text { density (no. fruit } / \\
\mathrm{cm}^{2} \text { TCSA)v }\end{array}$ & $\begin{array}{l}\text { Yield } \\
(\mathbf{k g})^{\mathbf{u}}\end{array}$ & $\begin{array}{c}\text { Fruit } \\
\text { wt }(g)^{u}\end{array}$ & $\begin{array}{c}\text { Yield efficiency } \\
\left(\mathrm{kg} \cdot \mathrm{cm}^{-2} \text { TCSA }\right)^{\mathrm{t}}\end{array}$ \\
\hline \multicolumn{8}{|c|}{2010} \\
\hline $\mathrm{F}^{\mathrm{r}}$ & $169 \mathrm{ab}$ & $111 \mathrm{a}$ & $7.2 \mathrm{ab}$ & $4.6 \mathrm{a}$ & $24.0 \mathrm{a}$ & $217 \mathrm{~b}$ & $0.99 \mathrm{a}$ \\
\hline $\mathrm{F}-\Delta^{\mathrm{q}}$ & $143 \mathrm{ab}$ & $100 \mathrm{a}$ & $5.8 \mathrm{abc}$ & $4.0 \mathrm{a}$ & $23.5 \mathrm{a}$ & $238 \mathrm{ab}$ & $0.93 \mathrm{a}$ \\
\hline
\end{tabular}

${ }^{2}$ Means of seven observations.

yean fruit number after treatments were applied.

${ }^{x}$ Mean fruit number at harvest.

${ }^{w}$ Mean crop density after treatments were applied; TCSA $=$ trunk cross-sectional area; 1 fruit $/ \mathrm{cm}^{2}=6.4516$ fruit $/$ inch ${ }^{2}$.

${ }^{\mathrm{M}}$ Mean crop density at harvest.

"l $\mathrm{kg}=2.2046 \mathrm{lb}, \mathrm{l} \mathrm{g}=0.0353 \mathrm{oz}$.

tYield efficiency $=$ yield per square centimeter TCSA; $1 \mathrm{~kg} \cdot \mathrm{cm}^{-2}=14.2233 \mathrm{lb} / \mathrm{inch}^{2}$

s'Mean separation within columns by Tukey's honest significance test at $P=0.05$.

${ }^{\mathrm{r}} \mathrm{F}$ is the number of fruit remaining after hand-thinning treatment with the hand-thinning gauge [Equilifruit; Institut National de la Recherche Agronomique (INRA), Montpelier, France]. Use of $\mathrm{F}$ will result in $\approx 6$ fruit $/ \mathrm{cm}^{2}$ branch cross-sectional area (BCSA). Branches were fitted with the hand-thinning gauge $3 \mathrm{~cm}$ ( 1.2 inches) from the trunk.

${ }^{\mathrm{q}} \operatorname{Delta}(\Delta)$ is an adjustment factor of the hand-thinning gauge, and is used to increase or decrease the number of fruit per unit BCSA. To decrease or increase intensity of handthinning treatment, $\Delta$ is added or subtracted to $\mathrm{F}$

PTrees were hand-thinned using a spacing heuristic of 7 to 8 inches (17.8 to $20.3 \mathrm{~cm}$ ) between solitary fruit.

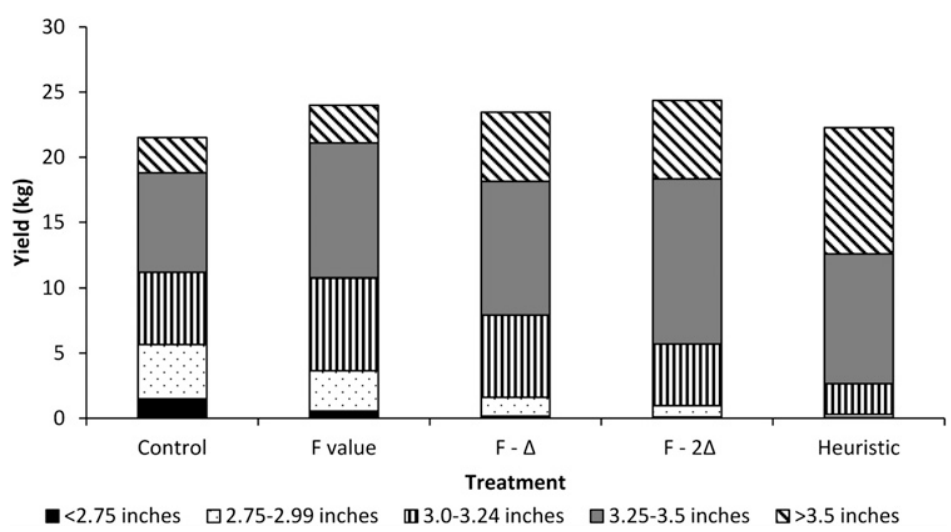

Fig. 4. Fruit size distribution of five hand-thinning treatments imposed on 'Honeycrisp' apple in 2010. The $\mathrm{F}$ value is the target number of fruit remaining after hand-thinning treatment with the hand-thinning gauge [Equilifruit; Institut National de la Recherche Agronomique (INRA), Montpelier, France]. Use of the F value will result in $\approx 6 \mathrm{fruit} / \mathrm{cm}^{2}\left(38.7\right.$ fruit $\left./ \mathrm{inch}^{2}\right)$ branch cross-sectional area (BCSA). Delta $(\Delta)$ is an adjustment factor of the hand-thinning gauge, and is used to increase or decrease the number of fruit per unit BCSA. To increase intensity of hand-thinning treatment, $\Delta$ or $2 \Delta$ were subtracted from the $F$ value. Heuristic treatment entailed spacing a solitary fruit every 7-8 inches of branch length. Data are a summary of individual fruit weights of all fruit of whole trees, with six replicate trees per treatment; 1 inch $=2.54 \mathrm{~cm}, 1 \mathrm{~kg}=2.2046 \mathrm{lb}$.

fruit throughout the canopy. These heuristics can vary widely, as personal experience is a frequent driver of the intensity of hand-thinning treatment. The hand-thinning gauge provides a target crop load of apple by using limb circumference as predictor of bearing surface. Therefore, if the bearing surface of a limb is substantially altered by pruning, the disc will not provide an appropriate estimate of the number of fruit that can be supported by the selected limb. We do not recommend the use of the hand-thinning gauge on limbs subjected to bench cuts (heading cuts), since bearing surface has been substantially manipulated. Apple trees trained to systems that manage bearing surface with renewal pruning are likely compatible with use of the hand-thinning gauge.

We recommend that the handthinning gauge be used as a training tool. After using the disc for a few hours, workers should be able to readily relate limb size to the number of fruit that can best be supported.

Since the hand-thinning gauge defines a target for apple crop load, there are several potential uses for this technology. While not formally tested, potential uses of the hand-thinning gauge include assessing the initial fruit set, defining targets for chemical thinning, estimating severity of frost damage (by comparing the number of viable blossoms per unit BCSA to the F value), and perhaps as a template for selective mechanized thinning.

\section{Implications for growers}

The hand-thinning gauge is a round, plastic disc with 11 semicircular notches of varying diameters along its perimeter. At each notch, there are two corresponding values that are of interest to the user: the $\mathrm{F}$ value and $\Delta$. The $\mathrm{F}$ value is the number of fruiting spurs or fruit that should remain after spur extinction and/or hand-thinning treatments. Use of the $\mathrm{F}$ value during hand-thinning will result in $\approx 6$ fruit/ $\mathrm{cm}^{2}$ BCSA. To consistently increase or decrease the number of fruit (or fruiting spurs) per unit BCSA, $\Delta$ can be added or subtracted to the $\mathrm{F}$ value.

Since the hand-thinning gauge uses the cross-sectional area of a given limb to estimate bearing surface, major alterations of the bearing surface may prevent proper use of the tool. For example, bench cuts can result in 
an overestimate of the number of fruit that can be best supported. We evaluated the use of the hand-thinning gauge on three cultivars trained to tall spindle. In all cultivars, trees thinned to the specifications of the $F$ value maintained yields comparable to control trees while increasing the proportion of fruit in large size categories. Our work demonstrates that the handthinning gauge is effective on tall spindle trees with renewal style pruning. After using the disc for a few hours, the user becomes proficient in relating limb size to an appropriate fruit number. The disc should be used as a training device and after sufficient experience is obtained by the worker, the disc should only be used to recalibrate as needed.

\section{Literature cited}

Batjer, L.P., H.D. Billingsley, M.N. Westwood, and B.L. Rogers. 1957. Predicting harvest size of apples at different times during the growing season. Proc. Amer. Soc. Hort. Sci. 70:46-57.

Davison, R.M., M. van Geldermalsen, J.N. Galletly, and C.B. Bateup. 1979. Selective size thinning in apples to improve fruit size and profitability. Orchardist N.Z. 52:279281.
Forshey, C.G. and D.C. Elfving. 1977. Fruit numbers, fruit size, and yield relationships in 'McIntosh' apples. J. Amer. Soc. Hort. Sci. 102:399-402.

Forshey, C.G. and D.C. Elfving. 1979. Branch samples for yield and fruit size comparisons in apple. HortScience 14: $143-144$.

Gasperini, F. 2012. Good point - Labor outlook is poor. Good Fruit Grower. 18 June 2013. <http://goodfruit.com/ Good-Fruit-Grower/January-1st-2012/ Good-Point-Labor-outlook-is-poor/>.

Gourley, J.H. and F.S. Howlett. 1941. Modern fruit production. Macmillan, New York, NY.

Knight, J.N. 1980. Fruit thinning of the apple cultivar Cox's Orange Pippin. J. Hort. Sci. 55:267-273.

Lauri, P.-E., E. Terouanne, J.-M. Lespinasse, J.-L. Rengard, and J.-J. Kelner. 1995. Genotypic differences in the axillary bud growth and fruiting pattern of apple fruiting branches over several years: An approach to regulation in fruit bearing. Sci. Hort. 64:265-281.

Lauri, P.-E., M. Willaume, G. Larrive, and J.-M. Lespinasse. 2004. The concept of centrifugal training in apple aimed at optimizing the relationship between growth and fruiting. Acta Hort. 636:35-42.

Lespinasse, J.-M. and P.-E. Lauri. 1999. Intégration des nouveaux concepts de conduite dans le systeme solaxe. Revue Suisse de Viticulture Arboriculture et Horticulture 31:167-171.

Lombard, P.B., N.W. Callan, F.G. Dennis, N.E. Looney, G.C. Martin, A.R. Renquist, and E.A. Mielke. 1988. Towards a standardized nomenclature, procedures, values and units in determining fruit and nut tree yield performance. HortScience 23:813817.

Robinson, T.L., S.A. Hoying, and G.H. Reginato. 2006. The tall spindle apple production system. New York Fruit Qrtrly. 14:21-28.

Robinson, T., S. Lopez, K. Iungerman, and G. Reginato. 2009. Crop load management for consistent production of Honeycrisp apples. New York Fruit Qrtrly. 17:25-28.

Tustin, D.S., G.A. Dayatilake, K.C. Breen, and M.J. Oliver. 2012. Fruit set responses to changes in floral bud load: A new concept for crop load regulation. Acta Hort. 932:195-202.

Uriu, K. and O. Lilleland. 1959. Limb circumference measurements aid in the better evaluation of apple fruit thinning data. J. Amer. Soc. Hort. Sci. 74:67-71.

Westwood, M.N. and A.N. Roberts. 1970. The relationship between trunk crosssectional area and weight of apple trees. J. Amer. Soc. Hort. Sci. 95:28-30. 